\title{
Knowledge, Attitude and Practice of Tooth Morphology among Dental Students
}

\author{
Research Article
}

Mohamed Noufal Z1, K. R. Don $2^{2 *}$, Archana Santhanam ${ }^{3}$

${ }^{1}$ Saveetha Dental College and Hospitals, Saveetha Institute of Medical and Technical Sciences, Saveetha University, Chennai-77, India.

${ }^{2}$ Reader, Department of Oral and Maxillofacial Pathology, Saveetha Dental College and Hospitals, Saveetha Institute of Medical and Technical sciences, Saveetha University, Chennai-77, India.

${ }^{3}$ Assistant Professor, Department of Oral and Maxillofacial Pathology, Saveetha Dental College, Saveetha Institute of Medical and Technical Sciences, Saveetha University, Chennai-77, India.

\section{Abstract}

\begin{abstract}
Aim: The aim of the study was to analyse the knowledge, attitude and practice of tooth morphology among dental students. Introduction: Tooth morphology or dental anatomy is defined as the subject which deals with the external and internal structure of tooth development. Dental anatomy is taught as a basic dental subject in dental schools in India. The knowledge of dental anatomy has immense use in clinical practice in dentistry. However, few people feel that dental anatomy has no use and has to be removed from the curriculum.

Materials and Methods: The present study was a cross sectional study conducted in 2020, where a questionnaire consisting of 10 questions were distributed to 200 dental students of different years of study. Google forms are used to collect the response. Survey was carried out using pre-existing, self administered, structural and online based questions. Data was analysed using a statistical package for the social sciences SPSS software.

Results: A total of 200 responses from the dental students were received. In total $33.3 \%$ of participants agreed that understanding tooth morphology helps in identification of primary and permanent teeth. $30.8 \%$ of participants agreed that knowing tooth morphology helped me to do my clinical work with confidence.

Conclusion: The present study revealed that the dental students have moderate knowledge of tooth morphology and moderately agree on its importance in professional dental practice.
\end{abstract}

Keywords: Dental Anatomy; Tooth Morphology; Knowledge, Awareness.

\section{Introduction}

Dental anatomy is an important component of dental curriculum in the programs of dentistry in India [1]. Tooth morphology or dental anatomy is defined as the subject which deals with the external and internal structure, morphology, function, eruption and shedding of all the teeth in the mouth [2]. Tooth morphology in a subject which explains about both the primary and permanent teeth [3]. The knowledge of tooth morphology, forms the fundamental basics for all the fields of dentistry [4]. Tooth impart many important functions in life such as for mastication purpose, phonation, speech and very importantly gives aesthetic value and feature to our face [5]. Knowledge of tooth morphology also plays an important role in restorative treatments, to achieve functional occlusal relationship, aesthetics, phonation and forensic investigation [6]. Also knowledge of dental anatomy/tooth morphology, helps in the prevention of dental diseases, endodontic and orthodontic therapy, forensic investigation, anthropological studies, fabrication of fixed and removable prosthesis and for procedures such as placement of rubber dams and matrix bands [7]. The practical tooth morphology classes are to improve, the manual skills which have paved the way to meet the clinical challenges [8].

However, there are a lot of different opinions whether to retain or ban the dental anatomy subject for future graduates as many of current graduates feel that tooth carving is an old age technique which has no use in the current or future graduates. Also, they feel learning tooth morphology only makes the student a great

*Corresponding Author:

Dr. K. R. Don,

Reader, Department of Oral and Maxillofacial Pathology, Saveetha Dental College and Hospitals, Saveetha Institute of Medical and Technical sciences, Saveetha University, Chennai-77, India.

E-mail: donkr.sdc@saveetha.com

Received: October 26, 2019

Accepted: November 26, 2019

Published: November 28, 2019

Citation: Mohamed Noufal Z, K. R. Don, Archana Santhanam. Knowledge, Attitude and Practice of Tooth Morphology among Dental Students. Int J Dentistry Oral Sci. 2019;S3:02:006:27-33. doi: http://dx.doi.org/10.19070/2377-8075-SI02-03006

Copyright: K. R. Don ${ }^{\circ} 2019$. This is an open-access article distributed under the terms of the Creative Commons Attribution License, which permits unrestricted use, distribution and reproduction in any medium, provided the original author and source are credited. 
technician.. Previously our team had conducted numerous original studies [9-15] and surveys [16-23] over the past 5 years. Now we are expanding our focus on epidemiology surveys. The idea of this survey stemmed from the current interest in our community. The present study was aimed to analyse knowledge, attitude and practice of tooth morphology among dental students.

\section{Materials and Methods}

A cross sectional study was designed in 2020 and performed among the dental students of our Institution. This study was approved by the institutional Review board. The study sample size was 200 dental students. The sampling techniques used was convenience sampling. To maintain liable privacy of act, we ensured to get information on their names or contact information. This study was conducted among three groups of study population namely BDS students, Interns and MDS students. A pre-existing, self administered, structural questionnaire was used as the study tool. The questions were developed from pre existing literature. The data collection is done in google forms. The responses were marked on a five-point Likert scale with options of strongly agree, agree, neutral, disagree and strongly disagree. The statistical analysis was performed using SPSS software. The statistical tests used were descriptive statistics and chi square tests. $\mathrm{p}$ value of $<0.05$ was taken to be statistically significant. Confidence level was set at $95 \%$.

\section{Results}

A total of 200 completely filled questionnaires were received. From the 200 study population $73.6 \%$ are BDS students, $15.4 \%$ are intern and $10.9 \%$ are MDS. All the questions and the corresponding frequency of responses are shown is the Table 1.
In the present study, $15.9 \%$ have responded - Strongly Agree and $33.3 \%$ responded - Agree on Understanding tooth morphology helps in correct identification of primary and permanent teeth. 12.4\% have responded - Strongly Agree and 32.8\% responded - Agree on Confident in estimating the chronological age of a patient by visualising the teeth.

For the question Can identify all the landmarks on the teeth confidently because of its reinforcement through carving classes. 16\% have responded - Strongly Agree and 33.8\% responded - Agree and for the question Able to diagnose teeth anomalies because of my sound knowledge of normal tooth morphology. $22.3 \%$ have responded - Strongly Agree and 23.3\% responded - Agree.

For the question Knowing tooth morphology helps me to do my clinical work with confidence. $13.9 \%$ have responded - Strongly Agree and 30.8\% responded - Agree and for the question Tooth carving classes have tutored in registering and retaining the theory knowledge of tooth morphology efficiently. 15.4\% have responded - Strongly Agree and 29.8\% responded - Agree.

For the question Can design and perform cavity preparation for a tooth efficiently because of sound knowledge in measurements and morphology. 20\% have responded - Strongly Agree and $29.3 \%$ responded - Agree and for the question Subconscious knowledge of tooth morphology has transformed into a good teeth sculptor. 14.4\% have responded - Strongly Agree and 29.8\% responded - Agree.

For the question Tooth morphology carving helps in carving or retaining the lost tooth structure in clinics. 13\% have responded - Strongly Agree and 23.3\% responded - Agree and for the

Table 1. Table showing frequency of responses.

\begin{tabular}{|c|c|c|c|c|c|}
\hline Questions & $\begin{array}{l}\text { Strongly } \\
\text { Agree \% }\end{array}$ & $\begin{array}{c}\text { Agree } \\
\%\end{array}$ & $\begin{array}{c}\text { Neutral } \\
\%\end{array}$ & $\begin{array}{l}\text { Disagree } \\
\%\end{array}$ & $\begin{array}{c}\text { Strongly } \\
\text { Disagree \% }\end{array}$ \\
\hline $\begin{array}{c}\text { Understanding tooth morphology helps in correct identification } \\
\text { of primary and permanent teeth. }\end{array}$ & $15.90 \%$ & $33.30 \%$ & $28.30 \%$ & $19.40 \%$ & $2.90 \%$ \\
\hline $\begin{array}{l}\text { Confident in estimating the chronological age of a patient by visual- } \\
\text { izing the teeth. }\end{array}$ & $12.40 \%$ & $22.80 \%$ & $26.80 \%$ & $27.80 \%$ & $9.90 \%$ \\
\hline $\begin{array}{l}\text { Can identify all the landmarks on the teeth confidently because of } \\
\text { its reinforcement through carving classes. }\end{array}$ & $15.90 \%$ & $33.80 \%$ & $22.80 \%$ & $19.40 \%$ & $7.90 \%$ \\
\hline $\begin{array}{l}\text { Able to diagnose teeth anomalies because of my sound knowledge } \\
\text { of normal tooth morphology. }\end{array}$ & $22.30 \%$ & $23.30 \%$ & $19.40 \%$ & $24.30 \%$ & $10.40 \%$ \\
\hline $\begin{array}{l}\text { Knowing tooth morphology helps me to do my clinical work with } \\
\text { confidence. }\end{array}$ & $13.90 \%$ & $30.80 \%$ & $23.80 \%$ & $22.80 \%$ & $8.40 \%$ \\
\hline $\begin{array}{l}\text { Tooth carving classes have tutored in registering and retaining the } \\
\text { theory knowledge of tooth morphology efficiently. }\end{array}$ & $15.40 \%$ & $29.80 \%$ & $27.80 \%$ & $20.40 \%$ & $6.40 \%$ \\
\hline $\begin{array}{l}\text { Can design and perform cavity preparation for a tooth efficiently } \\
\text { because of sound knowledge in measurements and morphology. }\end{array}$ & $19.90 \%$ & $29.30 \%$ & $21.30 \%$ & $19.40 \%$ & $9.90 \%$ \\
\hline $\begin{array}{l}\text { Subconscious knowledge of tooth morphology has transformed } \\
\text { into a good teeth sculptor. }\end{array}$ & $14.40 \%$ & $29.80 \%$ & $20.90 \%$ & $23.80 \%$ & 10.95 \\
\hline $\begin{array}{l}\text { Tooth morphology carving helps in carving or retaining the lost } \\
\text { tooth structure in clinics. }\end{array}$ & $12.90 \%$ & $23.30 \%$ & $29.80 \%$ & $21.80 \%$ & $11.40 \%$ \\
\hline $\begin{array}{l}\text { Confident to apply tooth morphology knowledge as an investiga- } \\
\text { tion tool in forensic sciences. }\end{array}$ & $18.90 \%$ & $25.30 \%$ & $27.30 \%$ & $22.30 \%$ & $5.90 \%$ \\
\hline
\end{tabular}


question Confident to apply tooth morphology knowledge as an investigation tool in forensic sciences. $18.9 \%$ have responded Strongly Agree and 25.3\% responded - Agree.

\section{Discussion}

In our study, participants were questioned whether understanding tooth morphology helps in correct identification of primary and permanent teeth. 15.9\% have responded - Strongly Agree and $33.3 \%$ of the study population responded - Agree. On comparing three different study groups, it was found that out of 200 study participants, 23 BDS students have responded- Strongly Agree and 47 BDS students answered Agree, which was the highest response for this question. A chi square test comparison between different years of study showed $(p)=0.330$ which indicates statistically insignificant [Fig:1]. This finding is similar to a study done by Patil s et al 2019 [24], in which BDS students gave a more positive response of $43.2 \%$. This shows that much of the dental students don't feel that Understanding tooth morphology helps in correct identification of primary and permanent teeth, probably because of less number of practical training classes allotted to them.

For the question Confident in estimating the chronological age of a patient by visualising the teeth. $12.4 \%$ have responded - Strongly Agree and 22.8\% of the study population responded - Agree. On comparing three different study groups, it was found that out of 200 study participants, 16 BDS students have responded- Strongly Agree and 35 BDS students answered Agree, which was the highest response for this question. A chi square test comparison between different years of study showed $(p)=0.046$ which indicates statistically significant [Fig:2]. This finding is similar to a study done by Patil S et al 2019 [24]. in which BDS students gave a more positive response of $54.05 \%$. This shows that many of the dental students don't feel that Confident in estimating the chronological age of a patient by visualising the teeth, probably because of less number of practical training classes allotted to them.

For the question Can identify all the landmarks on the teeth confidently because of its reinforcement through carving classes. 16\% have responded - Strongly Agree and 34\% of the study population responded - Agree. On comparing three different study groups, it was found that out of 200 study participants, 23 BDS students have responded- Strongly Agree and 51 BDS students answered
Agree, which was the highest response for this question. A chi square test comparison between different years of study showed $(p)=0.879$ which indicates statistically insignificant [Fig:3]. This finding is similar to a study done by Patil S et al., 2019 [24], in which BDS students gave a more positive response of $50.4 \%$. This shows that many of the dental students don't feel that Can identify all the landmarks on the teeth confidently. It indicates more reinforcement needed during carving classes.

For the question Able to diagnose teeth anomalies because of my sound knowledge of normal tooth morphology. 22.3\% have responded - Strongly Agree and 23.3\% of the study population responded - Agree. On comparing three different study groups, it was found that out of 200 study participants, 35 BDS students have responded- Strongly Agree and 36 BDS students answered Agree, which was the highest response for this question. A chi square test comparison between different years of study showed $(p)=0.360$ which indicates statistically insignificant. This finding is similar to a study done by Patil S et al 2019, [24] in which BDS students gave a more positive response of $50.4 \%$. This shows that many of the dental students don't feel that Able can diagnose tooth anomalies, this emphasises the need for more importance of dental anatomy to the dentals students.

For the question Knowing tooth morphology helps me to do my clinical work with confidence.

13.9\% have responded - Strongly Agree and 30.4\% of the study population responded - Agree. On comparing three different study groups, it was found that out of 200 study participants, 19 BDS students have responded- Strongly Agree and 51 BDS students answered Agree, which was the highest response for this question. A chi square test comparison between different years of study showed $(p)=0.245$ which indicates statistically insignificant[Fig:4]. This finding is similar to a study done by Patil S et al 2019, [24] in which BDS students gave a more positive response of $63.06 \%$. This shows that many of the dental students don't feel that Knowing tooth morphology helps me to do my clinical work with confidence, probably because of the less number of practical training classes allotted to them.

For the question Tooth carving classes have tutored in registering and retaining the theory knowledge of tooth morphology effi-

Figure 1. Bar graph showing chi square analysis of comparison of students of different years of study on Understanding tooth morphology in correct identification of primary and permanent teeth. X-axis showing year of study and $\mathrm{Y}$-axis showing number of students. Blue denotes strongly agree, Red denotes agree, Green denotes neutral, Orange denotes disagree, Yellow denotes strongly disagree. Majority of BDS students (47 out of 148) have responded Agree on Understanding tooth morphology in correct identification of primary and permanent teeth, but comparison was not statistically significant. Chi square test $\mathrm{p}=0.330$ indicating statistically not significant.

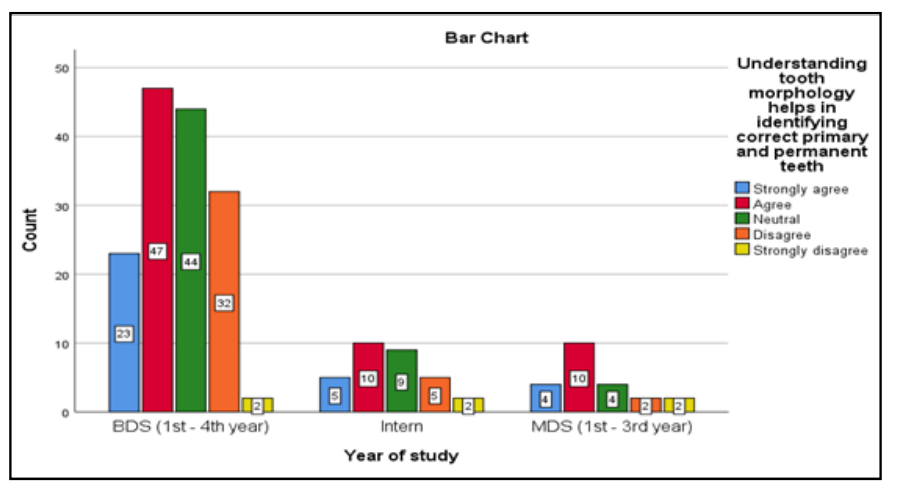


Figure 2. Bar graph showing chi square analysis ofcomparison of students of different years of study on Confident in estimating the chronological age of a patient by visualising the teeth. $\mathrm{X}$-axis showing year of study and $\mathrm{Y}$-axis showing number of students. Blue denotes strongly agree, Red denotes agree, Green denotes neutral, Orange denotes disagree, Yellow denotes strongly disagree. Majority of the BDS students (46 out of 148)have responded Neutral on Confidence in estimating the chronological age of a patient by visualising the teeth, and comparison was statistically significant. Chi square test $\mathrm{p}=\mathbf{0 . 0 4 6}$ indicating statistically significant morphology in correct identification of primary and permanent teeth, but comparison was not statistically significant. Chi square test $\mathrm{p}=\mathbf{0 . 3 3 0}$ indicating statistically not significant.

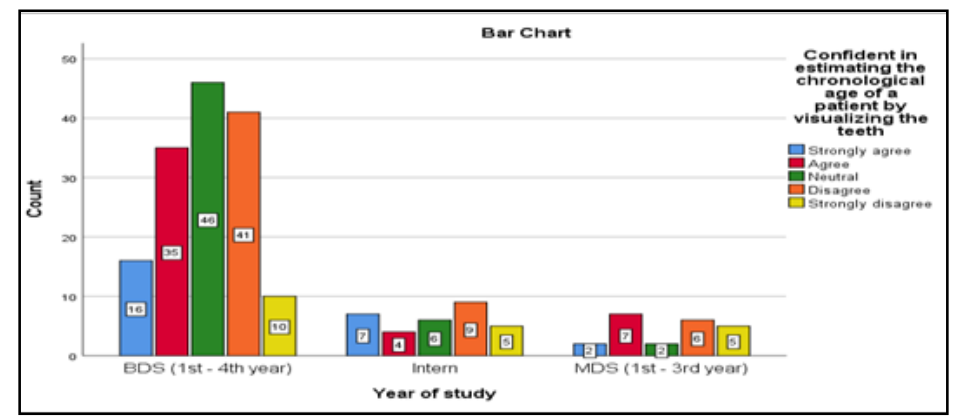

Figure 3. Bar graph showing chi square analysis of comparison of students of different years of study on Can identify all the landmarks on the teeth confidently because of its reinforcement through carving classes. $\mathrm{X}$-axis showing year of study and $\mathrm{Y}$-axis showing number of students. Blue denotes strongly agree, Red denotes agree, Green denotes neutral, Orange denotes disagree, Yellow denotes strongly disagree. Majority of BDS students (51 out of 148) have responded and agree on Can identify all the landmarks on the teeth confidently because of its reinforcement through carving classes, but comparison was not statistically significant. Chi square test $\mathrm{p}=0.879$ indicating statistically non significant.

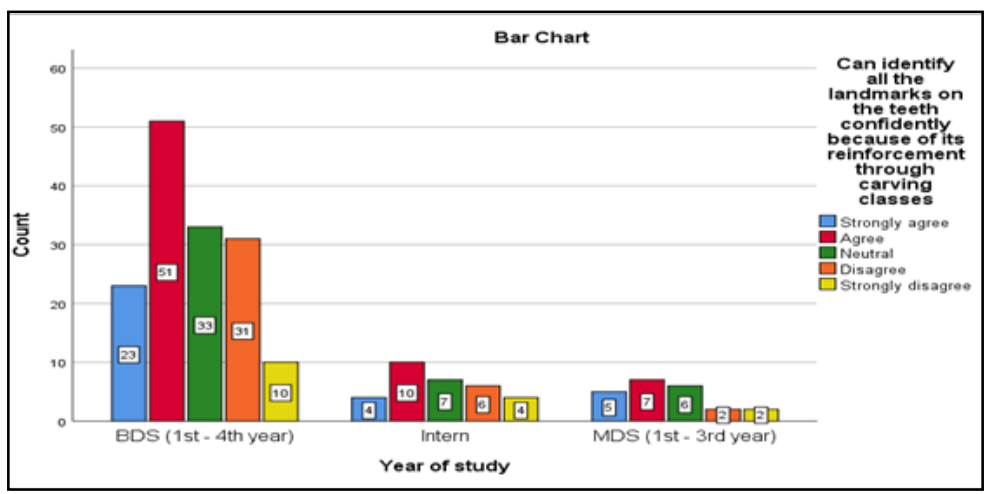

Figure 4. Bar graph showing chi square analysis of comparison of students of different years of study on Knowing tooth morphology helps me to do my clinical work with confidence. X-axis showing year of study and Y-axis showing number of students. Blue denotes strongly agree, Red denotes agree, Green denotes neutral, Orange denotes disagree, Yellow denotes strongly disagree. Majority of BDS students (51 out of 148) have responded and Agree on Knowing tooth morphology helps me to do my clinical work with confidence, but comparison was not statistically significant. Chi square test $p=0.245$ indicating statistically non significant.

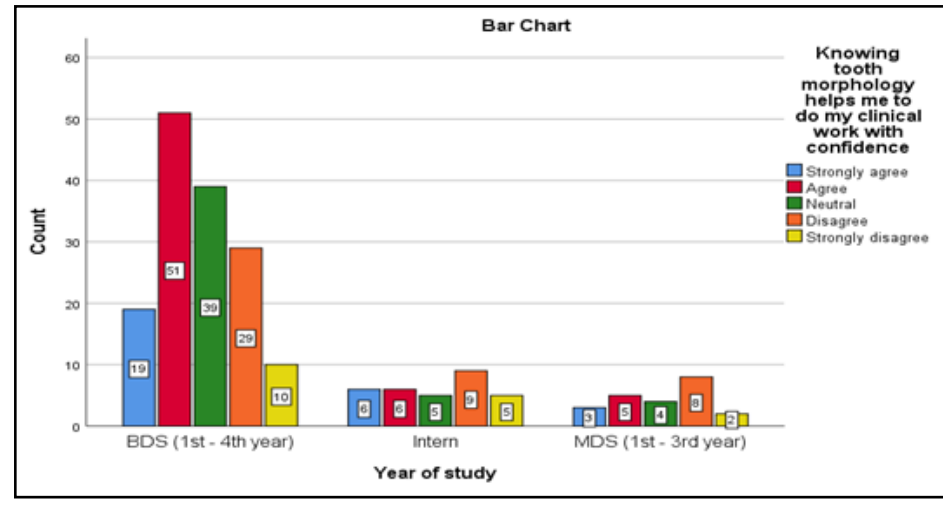

ciently. $15.4 \%$ have responded - Strongly Agree and 29.8\% of the study population responded - Agree. On comparing three different study groups, it was found that out of 200 study participants, 22 BDS students have responded- Strongly Agree and 48 BDS students answered Agree, which was the highest response for this question. A chi square test comparison between different years of study showed $(p)=0.342$ which indicates statistically insignificant. This finding is similar to a study done by Patil S et al 2019, [24] in which BDS students gave a more positive response of $48.6 \%$. This shows that many of the dental students don't feel that Tooth carving classes have tutored in registering and retaining the theory knowledge of tooth morphology efficiently, probably because of 
Figure 5. Bar graph showing chi square analysis of comparison of students of different years of study on Can design and perform cavity preparation for a tooth efficiently because of sound knowledge in measurements and morphology. X-axis showing year of study and Y-axis showing number of students. Blue denotes strongly agree, Red denotes agree, Green denotes neutral, Orange denotes disagree, Yellow denotes strongly disagree. Majority of BDS students (45 out of 148) have responded to a Agree on Can design and perform cavity preparation for a tooth efficiently because of sound knowledge in measurements and morphology, but comparison was not statistically significant. Chi square test $p=0.937$ indicating statistically non significant.

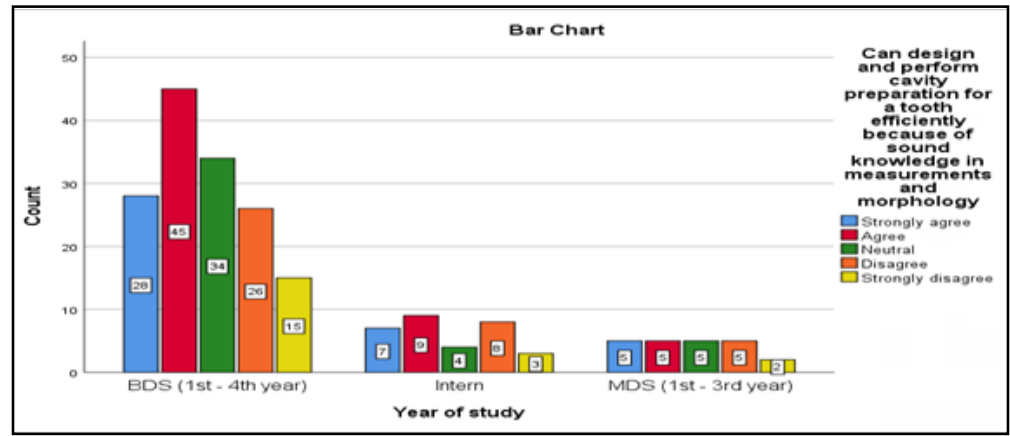

Figure 6. Bar graph showing chi square analysis of comparison of students of different years of study on Tooth morphology carving helps in carving or retaining the lost tooth structure in clinics. X-axis showing year of study and Y-axis showing number of students. Blue denotes strongly agree, Red denotes agree, Green denotes neutral, Orange denotes disagree, Yellow denotes strongly disagree. Majority of BDS students (48 out of 148) have responded neutral on Tooth morphology carving helps in carving or retaining the lost tooth structure in clinics, but comparison was not statistically significant. Chi square test $\mathrm{p}=0.365$ indicating statistically non significant.

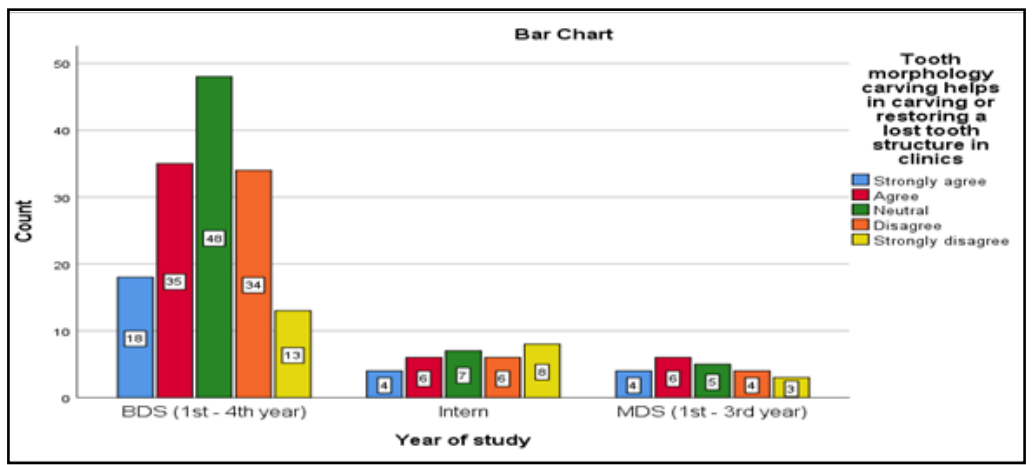

Figure 7. Bar graph showing chi square analysis of comparison of students of different years of study on Confident to apply tooth morphology knowledge as an investigation tool in forensic sciences. X-axis showing year of study and Y-axis showing number of students. Blue denotes strongly agree, Red denotes agree, Green denotes neutral, Orange denotes disagree, Yellow denotes strongly disagree. Majority of BDS students (44 out of 148) have responded neutral on Confidence to apply tooth morphology knowledge as an investigation tool in forensic sciences, but comparison was not statistically significant. Chi square test $\mathrm{p}=0.074$ indicating statistically non significant.

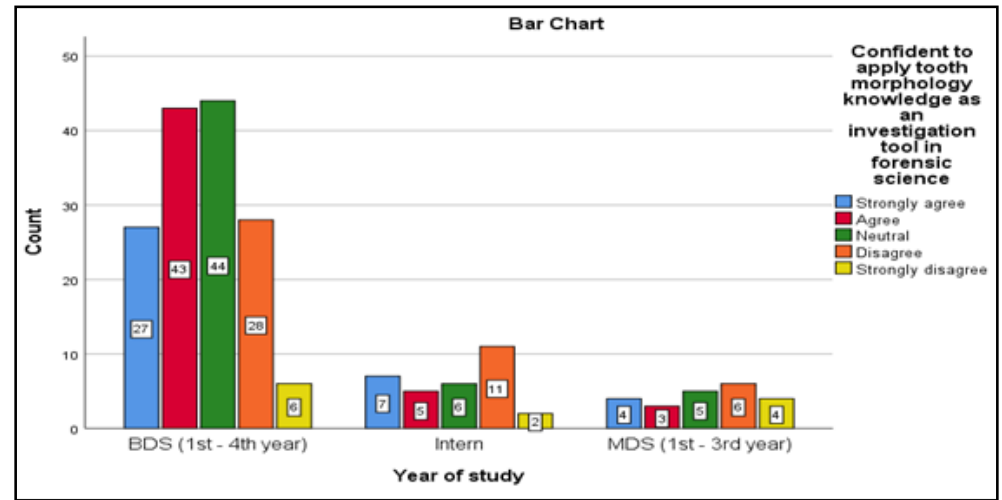

the less number of practical training classes allotted to them [2530].

For the question Can design and perform cavity preparation for a tooth efficiently because of sound knowledge in measurements and morphology. 20\% have responded-Strongly Agree and 29.1\% of the study population responded - Agree. On comparing three different study groups, it was found that out of 200 study participants, 28 BDS students have responded- Strongly Agree and 45 BDS students answered Agree, which was the highest response for this question. A chi square test comparison between different years of study showed $(p)=0.937$ which indicates statistically 
insignificant [Fig:5]. This finding is similar to a study done by Patil $S$ et al 2019, [24] in which BDS students gave a more positive response of $64.8 \%$. This shows that many of the dental students in our study don't feel that Can design and perform cavity preparation for a tooth efficiently because of sound knowledge in measurements and morphology, probably because of the less number of practical training classes allotted to them.

For the question Subconscious knowledge of tooth morphology has transformed into a good teeth sculptor. 14.4\% have responded - Strongly Agree and 29.8\% of the study population responded - Agree. On comparing three different study groups, it was found that out of 200 study participants, 23 BDS students have responded- Strongly Agree and 46 BDS students answered Agree, which was the highest response for this question. A chi square test comparison between different years of study showed $(p)=0.258$ which indicates statistically insignificant. This finding is similar to a study done by Patil S et al., 2019 [24], in which BDS students gave a more positive response of $44.1 \%$. This shows that many of the dental students don't feel that Subconscious knowledge of tooth morphology has transformed into a good teeth sculptor.

For the question Tooth morphology carving helps in carving or retaining the lost tooth structure in clinics. 13\% have responded - Strongly Agree and 23.3\% of the study population responded Agree. On comparing three different study groups, it was found that out of 200 study participants, 18 BDS students have responded- Strongly Agree and 35 BDS students answered Agree, which was the highest response for this question. A chi square test comparison between different years of study showed $(p)=0.365$ which indicates statistically insignificant [Fig:6]. This finding is similar to a study done by Patil S et al 2019, [24] in which BDS students gave a more positive response of $43.2 \%$. This shows that many of the dental students don't feel that Tooth morphology carving helps in carving or retaining the lost tooth structure in clinics.

For the question Confident to apply tooth morphology knowledge as an investigation tool in forensic sciences. $18.9 \%$ have responded - Strongly Agree and 25.3\% of the study population responded - Agree. On comparing three different study groups, it was found that out of 200 study participants, 27 BDS students have responded- Strongly Agree and 43 BDS students answered Agree, which was the highest response for this question. A chi square test comparison between different years of study showed $(p)=0.074$ which indicates statistically insignificant [Fig:7]. This finding is similar to a study done by Patil S et al 2019, [24] in which BDS students gave a more positive response of $38.7 \%$. This shows that many of the dental students don't feel that Confident to apply tooth morphology knowledge as an investigation tool in forensic sciences, probably because of the less number of practical training classes allotted to them.

The limitation of the study is the lesser sample size and the study involving the homogenous populations. This study was limited to one geographical location and the results cannot be generalised to a larger population.

\section{Conclusion}

In the present study, knowledge, attitude and practice of tooth morphology among dental students was found to be moderate.
Among BDS students, interns and MDS students, BDS students tend to agree more on the importance of tooth morphology sessions in the curriculum. Further studies with more population needed to assess the knowledge and importance of tooth morphology. Increased numbers of tooth morphology practical classes are the need of the hour.

\section{Acknowledgement}

The author would like to thank the study participants for their participation and their kind cooperation.

\section{Author Contribution}

Mohamed Noufal Z carried out the literature search, data collection, data analysis and manuscript writing. K.R.Don and Archana Santhanam conceived the study, participated in its design and coordinated and provided guidance to draft the manuscript. All the authors had equally contributed in developing the manuscript.

\section{References}

[1]. Alaa E, Younis S. Assessment of an Ergonomics Interventional Educational Program on Knowledge, Attitude, Practice and Behavior among a Group of Egyptian Dental Students [Internet]. Vol. 66, Egyptian Dental Journal. 2020. p. 623-32. Available from: http://dx.doi.org/10.21608/ edj.2020.79135

[2]. Aljrais MM, Ingle N, Assery MK. Oral-dental health knowledge, attitude and practice among dental and pharmacy students at Riyadh Elm University, KSA. J Int Oral Health. 2018 Jul 1;10(4):198.

[3]. Prabhu S, Joseph J, Saravanan S. Knowledge, attitude and perceived barriers towards practice of evidence based dentistry among Indian postgraduate dental students. IOSR J. Med. Dent. Sci . 2012;4(1):46-51.

[4]. Smadi L, Nassar OS. Oral \& dental health knowledge and attitude among nursing students. World. 2016;3(2):238.

[5]. Sriram N, Leelavathi L. Knowledge, Attitude and Practice Towards Evidence based Practice among Medical and Dental Students. Indian J Public Health Res Dev. 2019 Nov 1;10(11):3716.

[6]. Singh A, Purohit B. Knowledge, attitude and practice towards infection control measures and it's correlation among dental students in Bhopal city, Central India. Int J Infect Control. 2011;7.

[7]. Research CM, Case Medical Research. Knowledge, Attitude and Practice Among Undergraduate Dental Students, Cairo University Towards Ergonomics [Internet]. Case Medical Research. 2020. Available from: http:// dx.doi.org/10.31525/ct1-nct04237051

[8]. Agrawal R. Knowledge, attitude and perception of orthodontic treatment among dental students [Internet]. Vol. 6, International Journal of Dental Research. 2017;6- 3. Available from: http://dx.doi.org/10.14419/ijdr. v6i1.8604

[9]. Shree KH, Ramani P, Sherlin H, Sukumaran G, Jeyaraj G, Don KR, et al. Saliva as a diagnostic tool in oral squamous cell carcinoma-a systematic review with meta analysis. Pathol. Oncol. Res. 2019 Apr 15;25(2):447-53.

[10]. Abitha T, Santhanam A. Correlation between bizygomatic and maxillary central incisor width for gender identification. Braz. Dent. Sci. 2019 Oct 31;22(4):458-66.

[11]. Krishnan RP, Ramani P, Sherlin HJ, Sukumaran G, Ramasubramanian A, Jayaraj G, et al. Surgical Specimen Handover from Operation Theater to Laboratory: A Survey. Ann Maxillofac Surg. 2018 Jul-Dec;8(2):234-238. Pubmed PMID: 30693238.

[12]. Palati S, Ramani P, Sherlin HJ, Gheena S, Don KR, Jayaraj G, et al. Age Estimation of an Individual Using Olze's Method in Indian Population-A CrossSectional Study. IndianJ Med Forensic Med Toxicol. 2019;13(3):121-4.

[13]. Sarbeen JI, Gheena S. Microbial variation in climatic change and its effect on human health. Res J Pharm Technol. 2016;9(10):1777-81.

[14]. Harrita S, Santhanam A. Determination of Physical Height Using Clinical Crown Height of Deciduous Teeth. Indian J Med Forensic Med Toxicol. 2019;13(4):23-7.

[15]. Padavala S, Sukumaran G. Molar incisor hypomineralization and its prevalence. Contemp. Clin. Dent. 2018 Sep;9(Suppl 2):S246.

[16]. Palati S, Ramani P, Shrelin HJ, Sukumaran G, Ramasubramanian A, Don $\mathrm{KR}$, et al. Knowledge, Attitude and practice survey on the perspective of 
oral lesions and dental health in geriatric patients residing in old age homes. Indian J Dent Res. 2020 Jan-Feb;31(1):22-25.Pubmed PMID: 32246676.

[17]. Prasanna GE, Gheena S. A study of empathy across students from 4 health disciplines among 1st years and Final years. Res J Pharm Technol. 2016;9(9):1472-776.

[18]. Uma PK, Ramani P, Sherlin HJ. Knowledge about Legal Aspects of Medical Negligence in India among Dentists-A Questionnaire Survey. Medico Legal Update. 2020 Apr 9;20(1):111-5.

[19]. Hannah R, Ramani P, Sherlin HJ, Ranjith G, Ramasubramanian A, Jayaraj $\mathrm{G}$, et al. Awareness about the use, ethics and scope of dental photography among undergraduate dental students dentist behind the lens. Research Journal of Pharmacy and Technology. 2018;11(3):1012-6.

[20]. Gokul G, Abilasha S. Tooth sensitivity among residential university students in Chennai. Asian J Pharm Clin Res. 2016:63-5.

[21]. Ahad M, Gheena S. Awareness, attitude and knowledge about evidence based dentistry among the dental practitioner in Chennai city. Res J Pharm Technol. 2016;9(11):1863-6.

[22]. Manohar J, Abilasha R. A Study on the Knowledge of Causes and Prevalance of Pigmentation of Gingiva among Dental Students. Indian J Public Health Res Dev. 2019;10(8):95-100.

[23]. Sheriff K, Santhanam A. Knowledge and Awareness towards Oral Biopsy among Students of Saveetha Dental College. Res J Pharm Technol. 2018;11(2):543-6
[24]. Patil S, Sowmya SV, Rao RS, Raj T. Knowledge, attitude and practice of tooth morphology among dental students. J. adv. clin. res. insights. 2015 May 1;2(3):124-30.

[25]. M. Meenapriya, K R. Don. Occlusal Morphology of Permanent Mandibular Second Molar. International Journal of Current Advanced Research.2017;6(3):2703-2706.

[26]. S. Dhanalakshmi, KR Don. Cusp of Carabelli- Frequency, Distribution, Size And Clinical Significance. International Journal of Current Advanced Research. 2017; 6(4):3042-3044.

[27]. Trinaina Somas Kandhan., Gifrina Jayraj and K.R.Don. Proficiency testing of undergraduate dental studentsin permanent tooth morphology- a questionnaire based study. International Journal of Current Advanced Research. 2017; 6(3):2752-2754

[28]. Priyadharshini M, KR. Don. Prevalence of Two Variants of Permanent Mandibular Second Premolars. International Journal of Current Advanced Research.2017; 6(4):3541-3544

[29]. Noor Ul Huda, Don KR. Occlusal Morphology of Mandibular Third Molars. International Journal of Current Research. 2017; 9(5):50468-50471.

[30]. Sneha Hariharan, KR Don. Occlusal Morphology of Permanent Mandibular First Molar. IntJPharmSci RevRes.July - August 2017; 45(1): 93-96. 